\title{
Organics for Sustainable Food Security
}

\author{
Vijay Bhosekar*, Kris Nichols and Jeff Moyer \\ Rodale Institute, Pennsylvania, USA
}

*Corresponding author: Vijay Bhosekar, Rodale Institute, Pennsylvania, USA

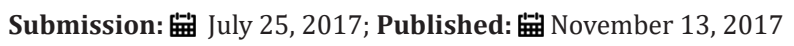

\begin{abstract}
Global population trajectories are exceeding prior projections, and now we must prepare for populations between 9.8 and 10.3 billion people by 2100 (4). In this scenario, United Nations Food and Agriculture Organization (FAO) has strongly advocated strategic programs for sustainable diets, which take a holistic approach to addressing dietary patterns that are presently unsustainable (5). To address the complexities and challenges in the agriculture and food systems, it's imperative we strongly focus on Sustainable/ Organic Food Systems approaches, which Rodale Institute is dedicated making strides in this direction for more than 60 years.
\end{abstract}

More than one billion people (across globe) mostly women and children are starving, having nutrition deficiencies, despite the fact there is enough food to go around. While hunger is not a matter of scarcity, it is worth noting that Organic, small- scale farming can feed the world [1]. More than 300 comprehensive world-wide studies show that organic farms outperformed conventional practices by $57 \%$ and that, Organic Agriculture could produce, on a per capita basis, to provide 2,640 to 4,380 calories per person per day which is much more than the suggested intake for healthy adults [1].

This implies/ proves the fact that research on holistic Organic food being carried out at Rodale Institute, would be of strategic importance/ significance, ensuring food sustainability with healthy nutrition diet [2]. The challenge for feeding the present global population (about 7 billion), expected to reach about 9 billion by 2050 and may exceed 10 billion by the end of century, could be feasible by switch over to Organic Food Production [3]. This would need more funding, more encouragement with increase in Organic farming acreage and higher incentives from government agencies, support from private institutions, as well as, motivating and energizing the new young farming community to feed the world [3].

People are hungry because the "global food system" we have built is out of control, and does not prioritize sustainable nutrition diets, which should be encouraged with more farm acreage for organic crops and production systems, as well as, preserving the natural resource base on which we all depend. Further, being out of proportion it only prioritizes corporate profits and props up" Unsustainable Food Production" while failing to actually feed people healthy diets [1]. Hence, to achieve holistic food nutrition and minimizing environmental concerns, Organics would be the only trusted agriculture strategy for future generation [1].Today's organic tent looks a lot different than yesterday [4,5]. It's bigger, younger and significantly more diverse than just a few years ago. In fact, inside that tent, it looks pretty much like most places in America, a new study by the Organic Trade Association (OTA) [6]. OTA also notes that if every farmer in US converted to organic production, we could eliminate 500 million pounds of persistent and harmful pesticides from entering the environment annually [6].

As the availability of organic food has become more main stream and the offerings of organic more varied, there's more diversity in those choosing organic. There no longer is a typical organic consumer. Organic is meeting the needs of a wide and multi-faceted culture, and the faces of organic buying families now mirror the demographics of the US population, as well as, the emerging economies in South Asia in terms of ethnic background [7]. Thus, Rodale Institute will continue to empower citizens to change the world by demanding and justifying Organic food only being the sustainable diet for generations to come.

Organic Farming can be profitable and organic food appeals to consumers as both a healthy and ethical choice. Beyond money though, organic farming practices also result in numerous environmental benefits:
1. Organic farming discourages environmental exposure to pesticides and chemicals
2. Organic farming builds healthy soil
3. Organic farming helps combat erosion
4. Organic farming fights the effects of global warming
5. Organic farming supports water conservation and water health
6. Organic farming discourages algae blooms
7. Organic farming supports animal health and welfare
8. Organic farming encourages biodiversity 


\section{Regenerative Agriculture}

Regenerative organic food production systems is an approach not using toxic chemicals in producing the food which eliminates risks to farm workers who plant, pick, handle, and pack products and to the environment, and organic standards for animal management have statistically reduced antibiotics and increased beneficial fatty acids in animal products [8]. Nutritional, toxicological and epidemiological studies of organic versus conventional food most often find that organic foods do contain more health giving properties and less toxic residues than their conventional counterparts, but debate over the healthfulness of organic food is most often concentrated around nutrient density or nutritive value and what this means for human health [8].

\section{Summary}

For more than sixty years, Rodale Institute has been researching the best practices of organic agriculture and sharing findings with farmers and scientists throughout the world, advocating for policies that support farmers, and educating consumers about how going organic is the healthiest option for people and the planet. We know how profoundly important organic food production systems is to our environment, our health, our families and our communities.

The society is well aware that, organics has the strength to not only feed the world, but feed the world well. Through first-rate scientific research and education and support for farmers, Rodale Institute will continue to empower citizens to change the world by demanding organic.

Through organic leadership, Rodale Institute would make all efforts and practices to improve the health and well-being of people and the planet having Core values, we empower each other to live our mission; our farm is a destination for inspiration; our research is a catalyst for change and we are a clear voice for informed choice.
Rodale Institute is committed to ground-breaking research in organic food production systems. Growing a future that will nourish and sustain generations to come. A future built upon rich, healthy soil and into which we can sink our roots.

The challenges facing food culture today are unlike anything we have experienced before, and they require revolutionary approaches to solving food production and sustainable nutrition problems. In short, new food production systems must deliver more human value, to those who need it most, with the least environmental harm. Furthermore, many climate change scientists and policy experts recognize that organic farming helps mitigate the threat of global warming by sequestering carbon and reducing greenhouse gas emissions from energy-intensive chemical fertilizers. All of these elements come together as Rodale Institute seeks to protect our health, the health of our families, the prosperity of communities and our environment.

\section{References}

1. (2006) Institute for Agriculture and Trade Policy, IATP.

2. (2011) Farming Systems Trial Report (30 years), Rodale Institute, USA, pp. 1- 21.

3. United Nations Population Division, Department of Economic and Social Affairs (2011) World Population Prospects, New York, United Nations.

4. Gerland P, Raftery AE, Sevčíková H, Li N, Gu D, Spoorenberg T (2014) World Population Stabilization unlikely this century. Science 346(6206): 234- 237.

5. Burlingame, Dernini (2012) Sustainable diets and biodiversity. Proc Int Sci Symp. On Biodiversity and Sustainable Diets United against Hunger, Nov 3-5, 2010. FAO, Rome.

6. (2014) US Organic Trade Association, a Report.

7. (2015) US Families Organic Attitudes and Beliefs, Survey Report, OTA.

8. Huber M (2011) “Organic Food and Impact on Human Health: Assessing the Status Quo and Prospects of Research, "NJAS- Wageningen. Journal of Life Sciences 58(3-4): 103-109. 